\title{
Konya ilindeki Birinci Basamak Sağlık Çalışanlarının Organ Bağışı Hakkındaki Bilgi Tutum Ve Davranışları
}

\section{Knowledge and Behavior of Organic Donation among Primary Health Care Workers in Konya Province}

\section{Burak Kurt', Dilek Öztaş², Hüseyin ilter ${ }^{3}$, Muhsin Akbaba ${ }^{4}$, Tolga Ozan ${ }^{3}$, Esra Güneş3}

' Kastamonu Merkez Toplum Sağlığı Merkezi, Kastamonu

2 Yıldıım Beyazıt Üniversitesi Tıp Fakültesi Halk Sağlığı Anabilim Dalı, Ankara

${ }^{3}$ T.C. Sağlık Bakanlığı Halk Sağlığı Genel Müdürlüğü, Ankara ${ }^{4}$ Çukurova Üniversitesi Tıp Fakültesi Halk Sağlığı Anabilim Dalı, Adana

Yazışma Adresi / Correspondence:

Burak Kurt

Hepkebirler Mah. Cumhuriyet Cad. No:64 (Eski Sağlık Müdürlüğü Binası) Merkez/KASTAMONU

\author{
T: +905336610533 E-mail: kurtburak@msn.com
}

Geliş Tarihi / Received : 27.04.2018 Kabul Tarihi / Accepted : 07.06.2018

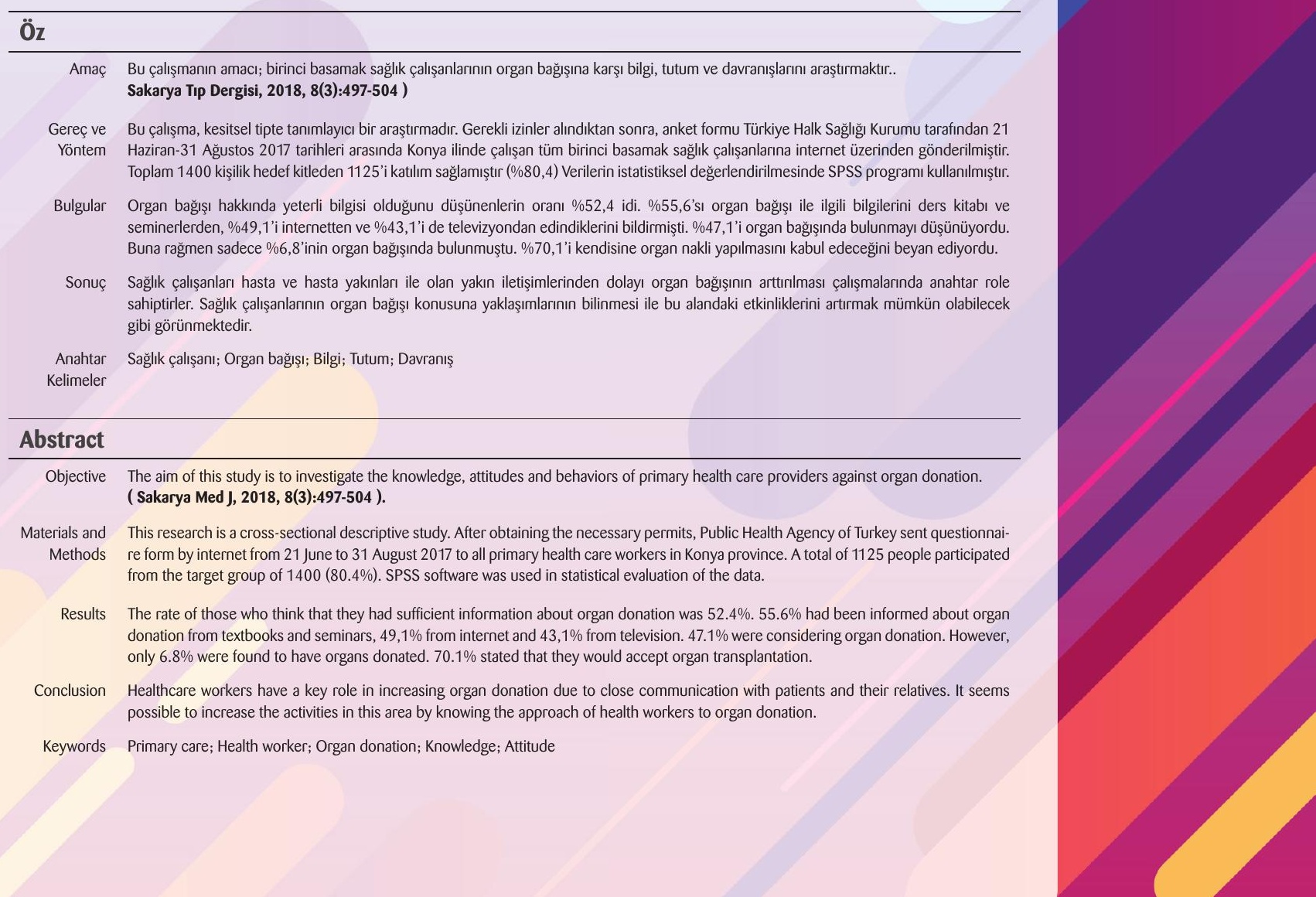


Sakarya TIp Dergisi $2018 ; 8(3): 497-504$

\section{Giriş}

Organ bağışı; kişi hayatta iken, serbest iradesi ile tıbben yaşamı sona erdikten sonra doku ve organlarının başka hastaların tedavisi için kullanılmasına izin vermesi ve bunu belgelendirmesidir. ${ }^{1,2}$ Ülkemizde kalp, akciğer, böbrek, karaciğer ve pankreas gibi organlar; kalp kapağı, gözün kornea tabakası, kas ve kemik iliği gibi dokular başarıyla nakledilebilmektedir. ${ }^{2,3}$

Organ bağışı, canlı vericiden ve kadavradan olmak üzere iki şekilde yapılır. Canlı vericiden organ naklinde organ yaşamakta olan sağlıklı bir kişiden alınır. Genellikle 4. dereceye kadar yakın akrabalardan uygun organlarından birinin alınıp nakil yapılabilmesine kanunlar izin vermektedir. Kadavradan organ naklinde ise organları alınan kişi tıbben ölmüştür. Bağışta bulunduğu organlar ihtiyacı olan ve doku uyumu bulunan hastalara nakledilir. ${ }^{4}$

Ülkemizde organ bağışıyla ilgili çalışmalar ve uygulamalar 2238 sayılı "Organ ve Doku Alınması, Saklanması, Aşılanması ve Nakli Yasası” ve “Organ ve Doku Nakli Hizmetleri Yönetmeliği” doğrultusunda yapılmaktadır. ${ }^{5,6}$

Avrupa ülkelerinde organ nakillerinin çoğu kadavradan temin edilirken ${ }^{7}$, ülkemizde ise tam tersine \%75-80 canlıdan nakiller yapılmaktadır. ${ }^{8}$ Bu sebeple, nakil sırasında bekleyen hasta sayısıyla, verici sayısı arasında çok büyük bir uçurum vardır ve bu sorun nakil programlarını oldukça kısıtlamaktadır.

Sağılı çalışanlarının eğitiminde organ nakline gerekli önemin verilmesi, bu konuda yeterli toplumsal bilincin oluşmasında etkili yollardan birisidir. ${ }^{9}$ Organ bağışlarını artırmak için, bu konuda bilgi veren sağlık çalışanlarının eğitim düzeyinin ve farkındalığının önemli olduğu gösterilmiştir. ${ }^{10}$

Bu çalışma birinci basamak sağılı çalışanlarının organ bağışına karşı bilgi, tutum ve davranışlarını araştırmaktadır. Toplumu yönlendirecek bu kişilerin, organ bağışı hakkında farkındalıklarını arttırmak ve konunun gündemde tutulması da amaçlanmıştır.

\section{Gereç ve Yöntemler}

\section{Araştırmanın Örneklemi ve Veri Toplama Aracı}

“Birinci Basamak Çalışanlarının Organ Bağışı İle illgili Algı Ve Bilgi Düzeylerinin Araştırılması” başIıklı anket formu, Türkiye Halk Sağlığı Kurumu Başkanlığı tarafından 21 Haziran-31 Ağustos 2017 tarihleri arasında internet üzerinden Konya ilinde çalışan tüm birinci basamak sağlık çalışanlarına gönderilmiştir. Toplam 1400 kişilik hedef kitleden 1125 ’i katılım sağlamıştır $(\% 80,4)$

\section{Verilerin Değerlendirilmesi}

Anket sonucunda elde edilen verilerin istatistiksel değerlendirilmesinde SPSS (Statistical Package for Social Science) 23.0 programı kullanılmıştır. Veriler, yüzde ve ortalama kullanılarak değerlendirilmiştir.

\section{Araștırmanın Etik Yönü}

Araştırmaya başlamadan önce Türkiye Halk Sağığı Kurumu Başkanlığı'ndan ve Ankara Yıldırım Beyazıt Üniversitesi Sosyal ve Beşeri Bilimler Etik Kurulu’ndan izin alınmıştır. Katılımcılardan ise ankete başlamadan önce araştırmanın amacı ve önemi hakkında bilgi verilip online izin alınmıştır. 


\section{Bulgular}

Katılımcıların \%64’ü kadın, \%36'sı erkekti. \%76,2'si 30-49 yaş arasındaydı. \%44,8'i pratisyen doktor, \%28,3'ü ebe, \%18'i hemşireydi. \%75,5’i 4 yıllık lisans ve üzeri eğitim seviyesine sahipti.

(Tablo 1)

\begin{tabular}{|c|c|c|c|}
\hline & & Sayı & Yüzde \\
\hline \multirow{2}{*}{ Cinsiyet } & Kadın & 720 & 64,0 \\
\hline & Erkek & 405 & 36,0 \\
\hline \multirow{5}{*}{ Yaş } & $20-29$ & 141 & 12,5 \\
\hline & $30-39$ & 421 & 37,4 \\
\hline & $40-49$ & 436 & 38,8 \\
\hline & $50-59$ & 116 & 10,3 \\
\hline & 60 ve üzeri & 11 & 1,0 \\
\hline \multirow{7}{*}{ Meslek } & Pratisyen Doktor & 504 & 44,8 \\
\hline & Ebe & 318 & 28,3 \\
\hline & Hemşire & 203 & 18,0 \\
\hline & Uzman Doktor & 50 & 4,4 \\
\hline & Sağlık Memuru & 19 & 1,7 \\
\hline & Tibbi Sekreter & 1 & 0,1 \\
\hline & Diğer & 30 & 2,7 \\
\hline \multirow{5}{*}{ Öğrenim Durumu } & illköğretim & 2 & 0,2 \\
\hline & Lise & 92 & 8,2 \\
\hline & Önlisans & 182 & 16,2 \\
\hline & Lisans & 747 & 66,4 \\
\hline & Yüksek Lisans ve üzeri & 102 & 9,1 \\
\hline
\end{tabular}

Katılımcıların \%52,4’ü organ bağışı hakkında yeterli bilgisi olduğunu düşünüyordu. Organ bağışı hakkındaki bilgileri en çok ders kitabı ve seminerlerden, bundan sonra ise internet ve televizyondan elde etmişlerdi. Organ bağışı talebinde bulunmamış bir kişiden organ nakli gerçekleştirebilme şartları sorulduğunda, \%83'ü birinci dereceden iki yakının onayı, \%43,6'sı beyin ölümü gerçekleşmesi, \%15,6’sı doktorun onay vermesi gerekir şeklinde yanıt vermiştir. Bağışlanabilen organlar sorulduğunda \%90'ın üzerinde böbrek, kalp, akciğer ve karaciğer bilinirken, akciğer, kalp kapağı, pankreas ve ince bağırsak nakli konusunda bilgi düzeyi eksik kalmıştır. (Tablo 2)

\begin{tabular}{|l|l|c|c|}
\hline Tablo 2. Katılımcıların Organ Bağışı Konusundaki Bilgi, Tutum ve Davranışları-1 \\
\hline & & Sayı & Yüzde \\
\hline \multirow{4}{*}{$\begin{array}{l}\text { Organ bağışı hakkında yeterli bilginiz } \\
\text { olduğunu düşünüyor musunuz? }\end{array}$} & Evet & 590 & 52,4 \\
\cline { 2 - 4 } & Hayır & 535 & 47,6 \\
\hline \multirow{4}{*}{$\begin{array}{l}\text { Organ bağıŞı hakkındaki bilgilerinizi nereden } \\
\text { edindiniz? }\end{array}$} & Ders Kitabı, Seminer & 625 & 55,6 \\
\cline { 2 - 4 } & Internet & 552 & 49,1 \\
\cline { 2 - 4 } & Televizyon & 485 & 43,1 \\
\cline { 2 - 4 } & Çevre & 252 & 22,4 \\
\cline { 2 - 4 } & Organ Bağışı Merkezi & 78 & 6,9 \\
\cline { 2 - 4 } & Diğer & 35 & 3,1 \\
\hline
\end{tabular}

Sakarya Tip Dergisi

2018;8(3):497-504

KURT ve Ark.

Konya lilindeki Birinci Basamak Sağlık Çallşanlarinın

Organ Bağsıi Hakkndaki Bilgi Tutum Ve Davranişlar! 
belirtmemiş, \%12,3'ü konu hakkında yeterli bilgisi olmadığını ifade etmiş, \%10,7'si dini nedenleri öne sürmüş, \%8,8'i organlarını almak için ölüm kararının erken verileceğini düşünmüş, \%8,6'sı organ mafyası ile ilgili endişeleri olduğunu belirtmiş, $\% 5,1$ 'i organlarını istemediği insanlara verileceğini düşünmüş ve \%4,1’i vücut bütünlüğünün bozulacağını düşünmüştü. (Tablo 4)

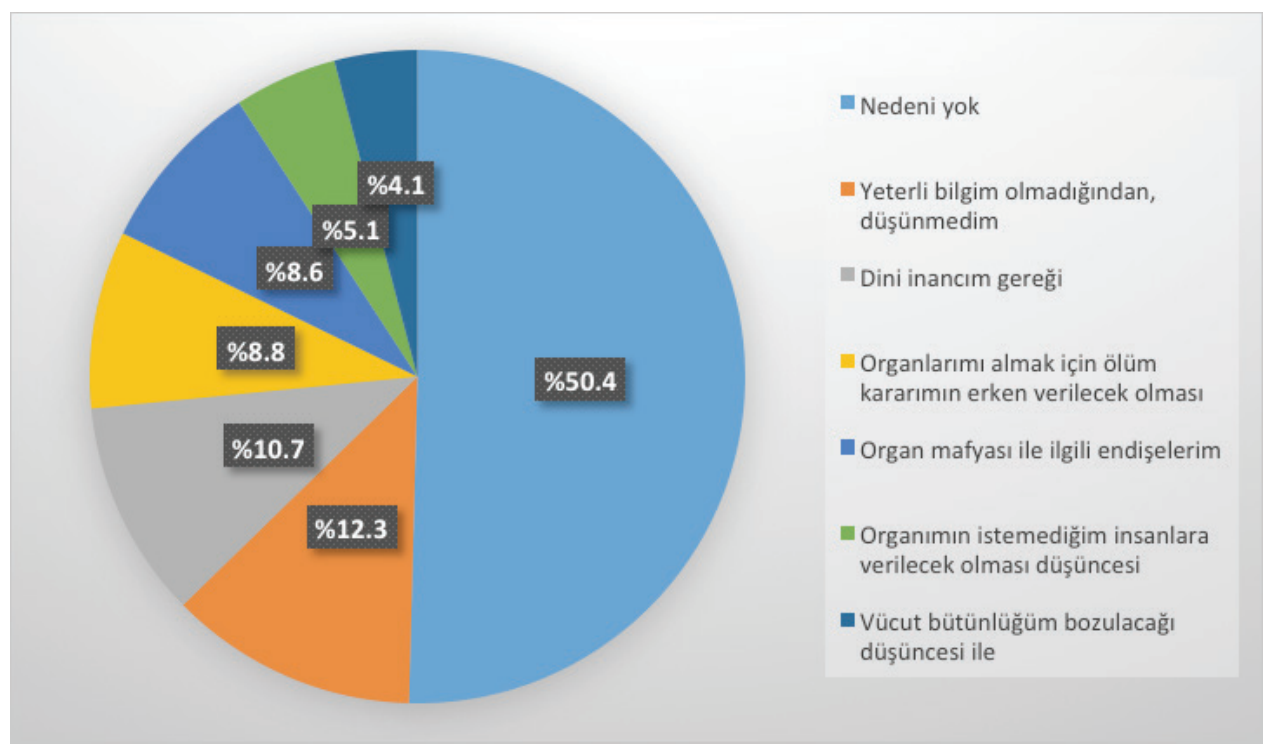

Şekil 1. Katılımcıların Organ Bağışı Yapmak İstememe Nedenleri

\section{Tartışma}

Birinci basamak sağlık çalışanlarının organ bağışı hakkındaki bilgi tutum ve davranışlarını belirlemeyi amaçladığımız bu çalışmada, organ bağışı hakkında yeterli bilgisi olduğunu düşünenlerin oranı $\% 52,4$ idi. Aydın'da üniversite hastanesi personeli üzerinde yapılan çalışmada ${ }^{11}$ bu oran $\% 50,2$, Afyon'da sağlık çalışanları ve hastalar üzerinde yapılan çalışmada ${ }^{12}$ ise $\% 49$ olarak bulunmuştur. Kişilerin eğitim düzeyinin artırılmasıyla beraber, organ bağı̧s sayılarının da artacağını düşünüyoruz. Çalışmamıza katılanların \%55,6'sı organ bağışı ile ilgili bilgilerini ders kitabı ve seminerlerden, $\% 49,1$ ' $i$ internetten ve $\% 43,1$ 'i de televizyondan edindiklerini bildirmişti. Diyarbakır'da lise öğrencileri üzerinde yapılan araştırmada \%57.6 ile radyo-tv ilk sırada yer alırken, \%38.1'i okuldan, \%36.2'si internetten, \%33.4'ü gazete ve dergilerden, \%31.5’i sağlık kuruluşundan, \%10.9'u ise diğer (anne, baba, arkadaş vs.) kaynaklardan bilgi edindiklerini belirtmişlerdi. ${ }^{13}$ Organ bağışı ile ilgili olumlu görüş oluşturulması için yayın organlarına, özellikle görsel medyaya, önemli görevler düşmektedir. Organ bağışını destekleyici programların yapılarak toplumun bilgilendirilmesi, toplum tarafından sevilen kişilerce konunun işlenmesi bağış oranını önemli ölçüde arttırabilecektir.

Daha önceden organ bağısıı talebinde bulunmamış bir kişiden hangi şartlarda organ nakli gerçekleştirilebilir diye sorulduğunda, katılımcıların \%83'ü 1. Dereceden yakının onayı, \%43,6'sı beyin ölümünün gerçekleşmesi, \%15,6'sı doktorun onay vermesi, gereklidir şeklinde cevap vermiştir. Isparta'da üniversite personeli üzerinde yapılan çalışmada bu oranlar sırasıyla \%47,4, \%31,9 ve \% 8,1 şeklinde bulunmuştur. ${ }^{1}$ Beyin ölümünün daha düşük oranlarda bildirilmesi, insanların bu konuda bilgilerinin yeterli olmadığını göstermektedir. Bu sonuç organ bağışı ve nakliyle ilgili toplumdaki gerçek dışı inanışları göstermektedir.

Organ nakli kanununun 2014 değişikliğine göre; “ "tıbbi ölümün gerçekleştiğine, biri nörolog veya
Sakarya Tıp Dergisi $2018 ; 8(3): 497-504$

KURT ve Ark. Konya ilindeki Birinci Basamak Sağlık Çalısanlarnıı Organ Bağıși Hakkindaki Bilgi Tutum Ve Davranışlan 
Sakarya TIp Dergisi 2018;8(3):497-504

Çalışmamıza katılanların \%47,1'i organ bağışında bulunmayı düşünüyordu. Buna rağmen sadece \%6,8'inin organ bağışında bulunmuştu. Üniversite öğrencileri üzerinde yapılan bir çalışmada katılımcıların \%91.1'inin organ bağışlamayı düşündüğünü fakat sadece \%3.8'inin organ bağışında bulunduğunu saptanmıştır. ${ }^{15}$ Sağlık yüksekokulunda yapılan benzer bir çalışmada da katılımcıların \%98,8'inin organ bağışını önemli bulduğunu belirtmiş fakat \%94,7'si henüz organ bağışı yapmadığını ifade etmiştir. ${ }^{16}$ Bu sonuçlar organ nakli ve bağışının önünde psikolojik etkilerin olduğunu göstermektedir. Nakil ve bağış konusunda başarının artması için nakil merkezlerinde çalışan koordinatörlerin iletişim ve halkla ilişkiler konusunda eğitimli olması, psikolojik sorunların aşılmasında yararlı olacaktır.

Çalışmamızda akrabalarında ya da yakın çevresinde organ bağışında bulunanların oranı \%10,6 idi. Isparta'da çalışan tıp fakültesi personellerinde bu oran benzer olarak \%9,7 bulunmuştur. ${ }^{17}$ Kişilerin akraba veya yakın çevresinde organ bağışında bulunan bireylerin olması, organ bağışındaki deneyimleri gözlemlemek ve empati kurmak açısından önemlidir.

Çalışmamıza katılanların \%70,1’i kendisine organ nakli yapılmasını kabul edeceğini beyan etmişti. Aydın'da üniversite hastanesi personeli üzerinde yapılan çalışmada da bu oran benzer şekilde \%74,7 olarak bulunmuştu. ${ }^{11}$ kendisine organ bağışı yapılmasını kabul etmenin, başkasına bağış yapmaktan daha fazla oranda olması, kişilerin bağış işlemi sırasındaki kaygılarıyla ilgili olabilir.

Son olarak, katılımcılara organ bağışı yapmak istememe nedenleri sorulduğunda, \%50,4’ü herhangi bir neden belirtmemiş, \%12,3'ü konu hakkında yeterli bilgisi olmadığını ifade etmiş, \%10,7'si dini nedenleri öne sürmüş, \%8,8'i organlarını almak için ölüm kararının erken verileceğini düşünmüş, \%8,6'sı organ mafyası ile ilgili endişeleri olduğunu belirtmiş, \%5,1'i organlarını istemediği insanlara verileceğini düşünmüş ve \%4,1’i vücut bütünlüğünün bozulacağını düşünmüştü. Hemşirelik son sınıf öğrencilerinde yapılan bir araştırmada öğrencilerin organ bağışında bulunmayı istememe nedenlerinin başında; vücut bütünlüğünün bozulmasını istememe düşüncesi (\%33.3), organ mafyası ile ilgili kayglar (\%29.2), dinsel nedenler (\%26.4) ve organlarını almak için ölüm kararının erken verileceği (\%26.4) düşünceleri gelmekteydi ${ }^{18}$. Türkiye'de organ temininde yaşanan sıkıntılar incelendiğinde hem sağlık personeli hem de toplum düzeyinde eğitim eksikliğinin önemli bir yer aldığı görülmektedir. Organ nakli ve bağışı konusunda toplumun ve özellikle sağlık personelinin eğitimi ve bu konuda olumlu tutum içinde bulunmaları organ nakli ve bağışının sayısının artması için çok önemlidir. ${ }^{19}$ Ülkemizde Diyanet İşleri Yüksek Kurulu 1980 yılında 396 sayılı kararı ile organ naklinin İslam dinince uygun olduğunu bildirmiştir. ${ }^{20}$ Dini açıdan organ bağışının uygun olduğu topluma anlatılmalıdır.

\section{Sonuç}


tırılması çalışmalarında anahtar role sahiptirler. Bu kişiler potansiyel vericileri saptayarak, organ bağışına yönlendirebilirler. Örnek olması açısından organ ve doku nakli konusunda kendileri bağış̧̧ı olabilirler. Sağlık çalışanlarının organ bağışı konusuna yaklaşımlarının bilinmesi ile bu alandaki etkinliklerini artırmak mümkün olabilecek gibi görünmektedir.
Sakarya Tip Dergisi

2018;8(3):497-504

KURT ve Ark.
Konya ilindeki Birinci Basamak Sağılk Çalışanlarının

Organ Bağıșı Hakkindaki Bilgi Tutum Ve Davranışları 
1. Akış M, Katırcı E, Uludağ HY ve ark. Süleyman Demirel Üniversitesi Personelinin Organ Doku Bağısıı ve Nakli Hakkındaki Bilgi ve Tutumları. Süleyman Demirel Üniversitesi Tıp Fakültesi Dergisi 2008; 15(4): 28-33

2. Şıpkın S, Şen B, Akan S, Tuna Malak A. Onsekiz Mart Üniversitesi Tıp Fakültesi, ilahiyat Fakültesi ve Güzel Sanatlar Fakültesi Öğretim Elemanlarının Organ Bağıșına Bakıș Açılarının İncelenmesi. ADÜ Tıp Fakültes Dergisi 2010; 11(1): 19-25

3. Özdağ N. Organ Nakli Ve Bağışına Toplumun Bakışı. Cumhuriyet Üniversitesi Hemsirelik Yüksek Okulu Dergisi 2001; 5: 46-54

Sakarya TIp Dergisi 2018;8(3):497-504

KURT ve Ark Konya ilindeki Bírinci Basamak Sağık Çalıșanlarının Organ Bağısı. Hakkındaki Bilgi Tutum Ve Davranışları Hekimliği Dergisi 2009; 3(2): 1-8.
4. Doğan P, Toprak D. Organ nakli tanımı, kapsamı, dini ve kanuni yönü. Aile

5. Organ ve doku alınması, saklanması, aşılanması ve nakli hakkında kanun Erișke: http://www.mevzuat gov.tr/MevzuatMetin/1.5.2238.pdf

6. Organ ve doku nakli hizmetleri yönetmeliği. Erişke: http://www.mevzuat. gov.tr/Metin.Aspx?MevzuatKod=7.5.15860\&Mevzuatlliski=0\&sourceXm ISearch $=$ organ $\% 20 \mathrm{ve}$

7. Murphy PG, Smith M: Towards a framework for organ donation in the UK Br J Anaesth 2012;108 Suppl 1:i56-67

8. Okka B, Demireli O: Konya ilinde halkın organ bağıșı konusuna bakış açılarının değerlendirilmesi. Turkiye Klinikleri J Med Ethics 2008;16:148158

9. Najafizadeh K, Shiemorteza M, Jamali M, Ghorbani F, Hamidinia S, Assari S, Moghani-Lankarani M: Attitudes of medical students about brain death and organdonation. Transplant Proc 2009;41:2707-2710.

10. Mekahli D, Liutkus A, Fargue S, Ranchin B, Cochat P: Survey of first-year medical students to assess their knowledge and attitudes toward organ transplantation and donation. Transplant Proc 2009;41:634-638.

11. Cillimoğlu AÖ, Yılmaz S, Oğurlu M. Adnan Menderes Üniversitesi Hastanesi Personelinin Organ-Doku Bağıșı ve Nakli Hakkındaki Bilgi ve Düşünceleri. Türk Nefroloji Diyaliz ve Transplantasyon Dergisi, 2016, 25 (3) 254-262.
12. Efil S, Şişe Ş, Üzel H, Eser O. Afyon ilinde Halkın ve Afyon Kocatepe Üniversitesi Tıp Fakültesi Sağıık Çalışanlarının Organ Bağıșı Konusuna Illgilerinin Değerlendirilmesi. Gümüșhane Üniversitesi Sağlık Bilimleri Dergisi, 2013;2(3): 361-384

13. Çetin Y. Diyarbakır Kent Merkezinde Bulunan Ortaöğretim Öğrencilerinin Organ Bağıșı Ile Illgili Bilgi Düzeyi Ve Tutumları. Yüksek Lisans Tezi, Fırat Üniversitesi Sağlık Bilimleri Enstitüsü, 2013.

14. Organ ve doku alınması, saklanması, aşılanması ve nakli hakkında kanun (2594 sayllı Kanun ile değişik hali). Erişke: http://www.mevzuat.gov.tr/ MevzuatMetin/1.5.2238-19820121.pdf

15. Kılıç S, Koçak N, Türker T, Gürpınar H, Gülerik, D. Kız Üniversite Öğrencilerinin Organ Bağıșı Konusundaki Tutumları ve Bu Tutumlara Etki Eden Faktörler. Gülhane Tıp Dergisi, 2010; 52 (1): 36-40.

16. Vicdan AK, Peker S, Üçer B. Akşehir Sağlık Yüksekokulu Öğrencilerinin Organ Bağışı ile ilgili Tutumlarının Belirlenmesi. TAF Preventive Medicine Bulletin, 2011; 10 (2): 175-80.

17. Kara S, Salman Z, Öngel K: Süleyman Demirel Üniversitesi Tıp Fakültesi sağılk personelinin organ bağışına bakışı. Ankara Sağlık Hizmetleri Dergisi 2012;11:33-39.

18. Savașer S, Mutlu B, Çağlar S, Doğan Z, Canbulat N. Hemșirelik Son Sınıf Öğrencilerinin Organ Bağışına Bakışları. i.ü.F.N. Hem. Derg (2012) Cilt 20 - Sayı $1: 1-9$

19. Keçecioğlu, N. B. (2003). Organ Bağısıı Sayısını Artırmak İçin Uzun Vadelı Yatııım: Toplum Eğitimi. Diyaliz Transplantasyon ve Yanık, 14 (3): 163 166.

20. Diyanet İșleri Bașkanlı̆ı̆ Din ișleri Yüksek Kurulu 396 Saylı Kararı 1980. Erișke: http://www.diyanet.gov.tr/turkish/dy/Kurulkararlari. aspx?Konuld=1 